\title{
Acetaminophen Induces Alterations to the Renal Tubular Ultrastructure in a Rat Model of Acute Nephrotoxicity Protected by Resveratrol and Quercetin
}

\author{
El Acetaminofeno Induce Alteraciones en la Ultraestructura Tubular Renal en un \\ Modelo de Rata con Nefrotoxicidad Aguda Protegida por Resveratrol y Quercetina
}

Mohamed A. Haidara ${ }^{1,2}$; Bahjat Al-Ani' ${ }^{1}$, Refaat A. Eid ${ }^{3}$; Muataz E. D. Mohammed ${ }^{1}$; Fahaid Al-Hashem ${ }^{1}$ \& Mohammad Dallak $^{1}$

HAIDARA, M. A.; AL-ANI, B.; EID, R. A.; MOHAMMED, M. E. D.; AL-HASHEM, F. \& DALLAK, M. Acetaminophen induces alterations to the renal tubular ultrastructure in a rat model of acute nephrotoxicity protected by resveratrol and quercetin. Int. J. Morphol., 38(3):585-591, 2020.

SUMMARY: Acetaminophen (also called paracetamol, or APAP) induced nephrotoxicity is reported after accidental or intentional ingestion of an overdose of the drug. Renal tubular ultrastructural alterations induced by APAP overdose associated with the induction of biomarkers of kidney injury have not been investigated before. Also, we investigated whether the combined polyphenolic anti-inflammatory and antioxidants agents, resveratrol (RES) and quercetin (QUR) can protect against APAP-induced acute kidney injury. The model group of rats received a single dose of APAP $(2 \mathrm{~g} / \mathrm{kg})$, whereas the protective group of rats was pre-treated for 7 days with combined doses of RES (30 $\mathrm{mg} / \mathrm{kg})$ and QUR $(50 \mathrm{mg} / \mathrm{kg})$ before being given a single dose of APAP. All rats were then sacrificed one day post APAP ingestion. Harvested kidney tissues were prepared for transmission electron microscopy (TEM) staining and blood samples were assayed for urea, creatinine, and biomarkers of inflammation and oxidative stress. TEM images and blood chemistry analysis showed that APAP overdose induced kidney damage as demonstrated by substantial alterations to the proximal convoluted tubule ultrastructure, and a significant $(\mathrm{p}<0.05)$ increase in urea, creatinine, tumor necrosis factor-alpha (TNF-a), and malondialdehyde (MDA) blood levels, which were protected by RES+QUR. These findings indicate that APAP induces alterations to the renal tubular ultrastructure, which is inhibited by resveratrol plus quercetin, which also decreases blood levels of kidney injury biomarkers.

KEY WORDS: Renal tubule ultrastructure; Acetaminophen; Resveratrol; Quercetin; Rat model.

\section{INTRODUCTION}

Ingestion of a toxic dose of the analgesic drug, acetaminophen (APAP) is among the most common causes of acute liver and kidney injuries in humans and experimental animal models (Mour et al., 2005; McGill et al., 2012; Karaali et al., 2018). It is the most common agent of intentional self-harm and APAP poisoning claimed the life of 284 persons aged 12 years and over between 1993-1996 in England and Wales, UK (Hawton et al., 2004). In addition, about $50 \%$ of acute liver failure admitted cases in the United States of America are caused by APAP poisoning (Ostapowicz et al., 2002; Larson et al., 2005). APAP is metabolized in the liver and hepatotoxic metabolites that represents about $10 \%$ of the whole metabolites are rapidly inactivated by glutathione (GSH) to protect the hepatocytes (James et al., 2003). However, with the drug overdose for example, the elevated levels of liver toxic metabolites, mainly $\mathrm{N}$-acetyl-p-benzoquinoimine (NAPQI) rapidly deplete GSH and covalently modify cellular proteins leading to the generation of high levels of reactive oxygen species (ROS) and depletion of the ATP, which results in mitochondrial damage and hepatocyte and kidney injuries (Hinson et al., 2004). However, it was postulated that depletion of $90 \%$ of GSH in hepatocytes is critically necessary for the development of cell necrosis (Henderson et al., 2000). In addition, hepatic inflammatory cytokines are also reported to be involved in APAP-induced liver injury (Blazka et al., 1996).

Resveratrol and quercetin are polyphenolic antioxidants found in fruits, vegetables, and grains(Burda \& Oleszek, 2001; Cudmore et al., 2012). They have been widely known to have potent cardiovascular protective and therapeutic

\footnotetext{
${ }^{1}$ Department of Physiology, College of Medicine, King Khalid University, Abha 61421, Saudi Arabia.

${ }^{2}$ Department of Physiology, Kasr Al-Aini Faculty of Medicine, Cairo University, Cairo, Egypt.

${ }^{3}$ Department of Pathology, College of Medicine, King Khalid University, Abha 61421, Saudi Arabia.

FUNDING: This work was supported by the Research Deanship of King Khalid University, Grant/Award Number: KKU-Project No. R.G.P1./40/40
} 
HAIDARA, M. A.; AL-ANI, B.; EID, R. A.; MOHAMMED, M. E. D.; AL-HASHEM, F. \& DALLAK, M. Acetaminophen induces alterations to the renal tubular ultrastructure in a rat model of acute nephrotoxicity protected by resveratrol and quercetin. Int. J. Morphol., 38(3):585-591, 2020.

effects via scavenging ROS (Hung et al., 2000), antiinflammatory effects (Rogerio et al., 2007; Al-Ani, 2013), inhibition of lipid peroxidation and liver and kidney protection (Faghihzadeh et al., 2015; Zhang et al., 2017). Neither APAP-induced kidney ultrastructural alterations have been investigated before nor has the combination of resveratrol and quercetin been used before to study the protection of kidney tissue upon acetaminophen intoxication in an animal model. Therefore, this study was designed to investigate the tubular kidney nephron ultrastructural changes upon APAP intoxication and the degree of protection provided by resveratrol and quercetin, and compares it with the level of protection provided by these agents to known kidney injury biomarkers.

\section{MATERIAL AND METHOD}

Reagents and assay kits. Quercetin (C15H10O7, CAS Number 117-39-5) was purchased from Sigma-Aldrich (St. Louis, MO, USA) and was prepared daily and freshly by dissolving in a normal saline solution $(0.9 \% \mathrm{NaCl})$ to the final concentration of $50 \mathrm{mg} / \mathrm{ml}$. Resveratrol $(\mathrm{C} 14 \mathrm{H} 12 \mathrm{O} 3$, Cat No. R5010) was also purchased from Sigma-Aldrich (St. Louis, MO, USA) and was prepared daily and freshly by dissolving in a saline solution $(0.9 \% \mathrm{NaCl})$ containg 20 $\%$ hydroxypropyl cyclodextrin (American Maize-Products Co., Hammond, IN, USA) to a final concentration of $30 \mathrm{mg}$ / $\mathrm{kg}$. Assay kits for determination of malondialdehyde (MDA, Cat No. NWK-MDA01) were purchased from NWLSS (Vancouver, BC, Canada). ELISA kits for determination of TNF-a (Cat No. ab46070) was purchased from Abcam, Cambridge, UK.

Animals. All experimental procedures were approved by the medical research ethical committee at King Khalid University and according to the Guide for the Care and Use of Laboratory Animals published by the US National Institutes of Health (NIH publication No.85-23, revised 1996). Sprague Dawley rats $(n=18)$ weighing 170 $200 \mathrm{~g}$ were used in this study. All rats were bred and housed in the research center of King Khalid University, College of Medicine (Abha, Saudi Arabia), at temperature of $23 \pm$ $1{ }^{\circ} \mathrm{C}$ and a $12 \mathrm{~h}$ light: $12 \mathrm{~h}$ dark cycle. Rats had free access to tap water and fed standard laboratory chow during the acclimatization period.

Experimental study. After a one week adaptation period, rats were randomly assigned into 3 groups $(n=6$; each) and were distributed in their corresponding cages and classified as follows: (1) Control group: rats received normal saline daily for 7 days; (2) APAP intoxicated group
(Model group): rats received normal saline for 7 consecutive days and then given a single dose of APAP ( $2 \mathrm{~g} / \mathrm{kg}$, orally); and (3) RES+QUR+APAP group: rats were pre-treated with RES (30 mg/kg) and $50 \mathrm{mg} / \mathrm{kg}$ QUR for 7 consecutive days and then administered with a single dose of APAP $(2 \mathrm{~g} / \mathrm{kg}$, orally). APAP was administered to the desired groups one hour after the last dose of treatment on day 7 and all treatment in all groups were administered i.p. in a final volume of $1 \mathrm{ml}$. All animals were sacrificed at day 8 , and kidney tissue and blood were collected for microscopy and blood chemistry analysis.

Transmission electron microscopy (TEM). As we previously reported (Dallak et al., 2018), small pieces of 1 $\mathrm{mm}^{3}$ of kidney tissue was removed and immediately fixed in $2.5 \%$ glutaraldehyde for 6 hours and washed with phosphate buffer (0.1 M, PH 7.4). Post-fixation was made in $1 \%$ osmium tetroxide buffered to $\mathrm{PH} 7.4$ with $0.1 \mathrm{M}$ phosphate buffer at $4{ }^{\circ} \mathrm{C}$ for $1-2$ hours. The samples were washed in a phosphate buffer to remove excess fixative, dehydrated through ascending grades of ethanol followed by clearing in propylene oxide. The specimens were embedded in Araldite 502, to form gelatin capsules. Polymerization was obtained by placing the capsules at 60 ${ }^{\circ} \mathrm{C}$. Semi-thin sections $(\sim 1 \mathrm{~mm}$ thick) were stained with toluidine blue for orientation and observation. Ultra-thin sections $(100 \mathrm{~nm})$ were prepared using ultra-microtome and picked up on uncoated copper grids. Following double staining with uranyl acetate and lead citrate, three to five random micrographs for each section were examined and photographed using a JEM-1011-JEOL transmission electron microscope, Japan, Tokyo, at $80 \mathrm{Kv}$. The integrity of glomerular basement membrane (GBM) and podocyte foot processes $(\mathrm{PF})$ were assessed in 50 fields and given a semi-quantitative score of $0-3(0=$ no injury, $1=$ mild injury, $2=$ moderate injury, $3=$ severely diseased as shown by extensive areas of injury with the loss of the integrity of GBM and PF).

Determination of blood levels of urea, creatinine, TNFand MDA. At day 8, animals were sacrificed and blood levels of urea, creatinine, TNF- $\alpha$, and MDA were determined using ELISA kits according to the manufacturer's instructions.

Statistical analysis. The data was expressed as mean \pm standard deviation (SD). Data was processed and analyzed using the SPSS version 10.0 (SPSS, Inc., Chicago, Ill., USA). One-way ANOVA was performed followed by Tukey's post hoc test. Pearson correlation statistical analysis was done for detection of a probable significance between two different parameters. Results were considered significant if $\mathrm{p} \leq 0.05$. 


\section{RESULTS}

Induction of acute kidney injury in rats by APAP. We first sough to characterize the rat model of acute kidney injury induced by the nephrotoxic agent, APAP. Ingestion of a single toxic dose of APAP ( $\mathrm{g} / \mathrm{kg}$ body weight) by the model group of rats caused, after 24 hours, a sharp increase in biomarkers of acute kidney injury and abnormal proximal convoluted tubule ultrastructure (Fig. 1). APAP induced nephrotoxicity which caused a sharp increase in blood urea (Fig. 1A) and creatinine (Fig. 1B) compared to normal levels in the control group. TEM images of proximal convoluted tubular sections (Figs. 1C and 1D) confirmed kidney injury and abnormal changes to renal tubule ultrastructure. Representative TEM image (2500x) of kidney sections obtained from the model group (Fig. 1D) shows altered tubule ultrastructure; tubular cells with shrunken irregular heterochromatic nucleus and dilated nuclear envelope, vacuolated cytoplasm (V) and numerous irregularly dispersed mitochondria $(\mathrm{m})$ with electron-dense matrix, markedly variable sizes and bizarre shapes. Whereas, a TEM image of another renal tubule at similar magnification prepared from kidney sections of the control group (Fig. 1C) shows unremarkable ultrastructure of the proximal convoluted tubules.

Resveratrol plus quercetin inhibit biomarkers of inflammation and oxidative stress induced by APAP. To determine the level of inhibition of these biomarkers by combined injections of resveratrol and quercetin for 7 days prior to APAP intoxication; we measured blood levels of TNF- $\alpha$ (Fig. 2A) and MDA (Fig. 2B) in all rat groups. Compared with the control group, APAP caused a fourfold increase in both TNF- $\alpha$ and MDA that was significantly $(\mathrm{p}<0.05)$ inhibited by RES+QUR (Figs. 2A and 2B). However, the levels of TNF- $\alpha$ and MDA in the RES+QUR group were still significant $(\mathrm{p}<0.05)$ to the control group, which means a partial inhibition by RES+QUR.

Resveratrol plus quercetin inhibit biomarkers of kidney injury induced by APAP. To determine the level of inhibition of kidney injury biomarkers by combined injections of resveratrol and quercetin for 7 days prior to APAP intoxication; we measured blood levels of urea and creatinine. APAP caused a twofold and threefold increase in urea and creatinine, respectively, which was significantly $(\mathrm{p}<0.05)$ inhibited by RES+QUR (Figs. 3A and 3B). Also, the levels of urea and creatinine in the RES+QUR group were still significant $(\mathrm{p}<0.05)$ to the control group (Fig. 3). This means, a partial inhibition by RES+QUR.

Resveratrol plus quercetin protect renal proximal tubule ultrastructure against alterations induced by APAP. We assessed the integrity of renal proximal convoluted tubules (Fig. 4) in the model and treated groups using TEM analysis. Representative TEM images of proximal convoluted tubular sections obtained from the model group (APAP) (Fig. 4B) revealed tubular cells with shrunken irregular heterochromatic nucleus and dilated nuclear envelope, vacuolated cytoplasm
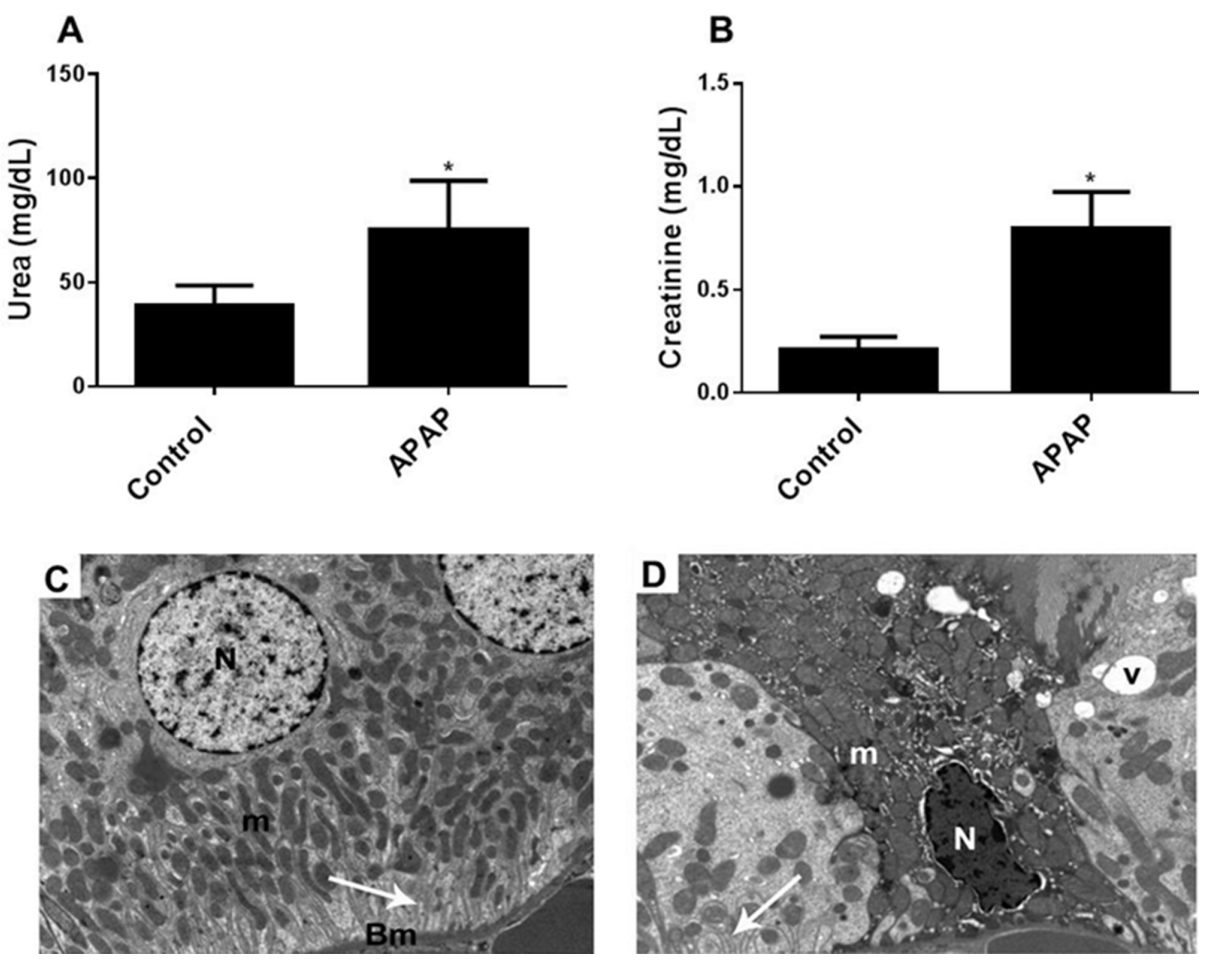

Fig. 1. Induction of acute kidney injury in rats by APAP. Blood levels of urea (A) and creatinine (B) were measured at the end of the experiment in the model group compared to the control group. Results represent the mean $( \pm \mathrm{SD})$, and experiments were performed in triplicate. $* \mathrm{p}<0.05$ versus control. (C and D). TEM images (2500x) of harvested tissues obtained from the kidney of model group (D) compared to control group (C) rats are visualized using transmission electron microscopy. Abbreviations: $\mathrm{N}$, nucleus; $\mathrm{m}$, mitochondria; $\mathrm{Bm}$, basement membrane; $\mathrm{V}$, vacuole. 
A

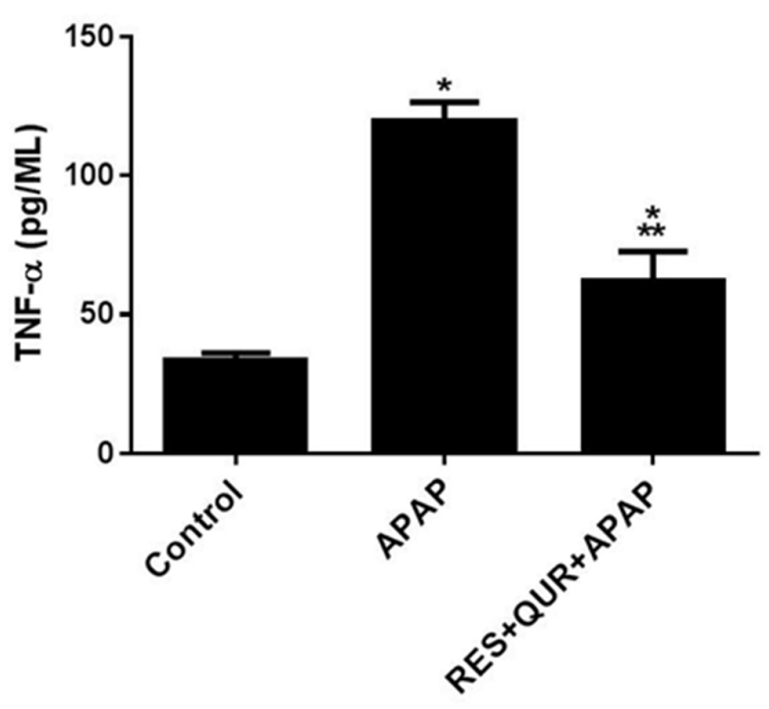

B

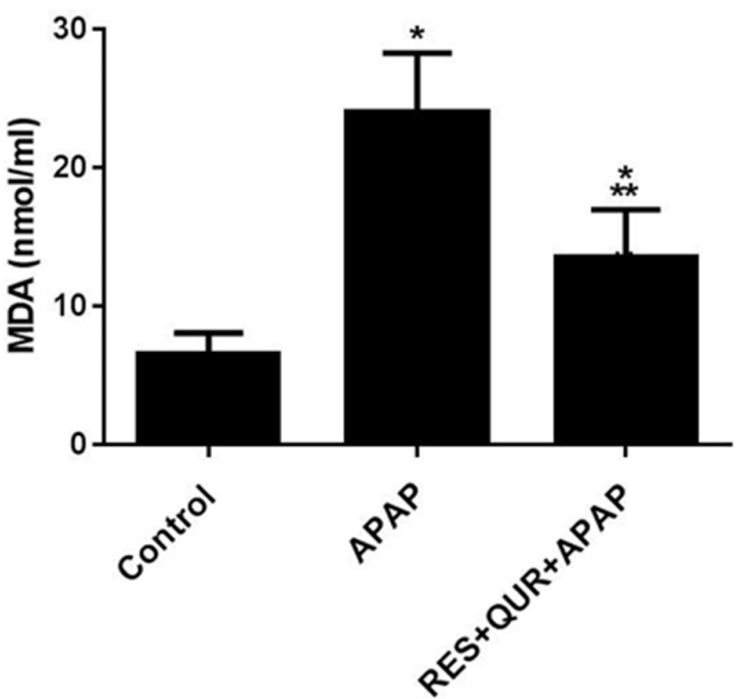

Fig. 2. Resveratrol and quercetin inhibit APAP-induced biomarkers of inflammation and oxidative stress in rats. Blood levels of TNF-? (A) and MDA (B) were measured at the end of the experiment in different groups of rats used in this study; Control group, APAP group, and RES+QUR+APAP group. Results represent the mean $( \pm \mathrm{SD}) ; \mathrm{n}=6$ for each group. Experiments were performed in triplicate. $* \mathrm{p}<0.05$ versus control, $* * \mathrm{p}<0.05$ versus APAP.

A

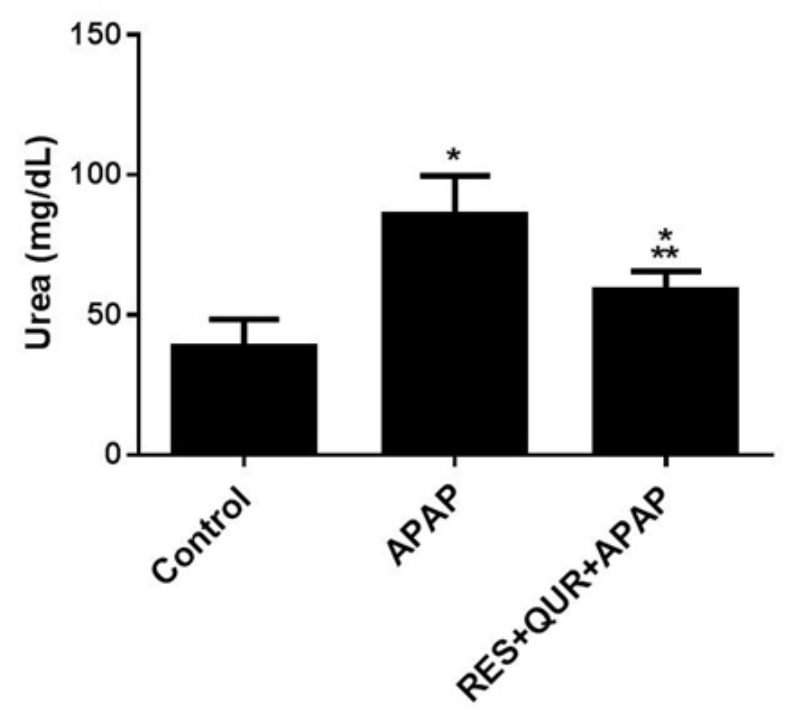

B

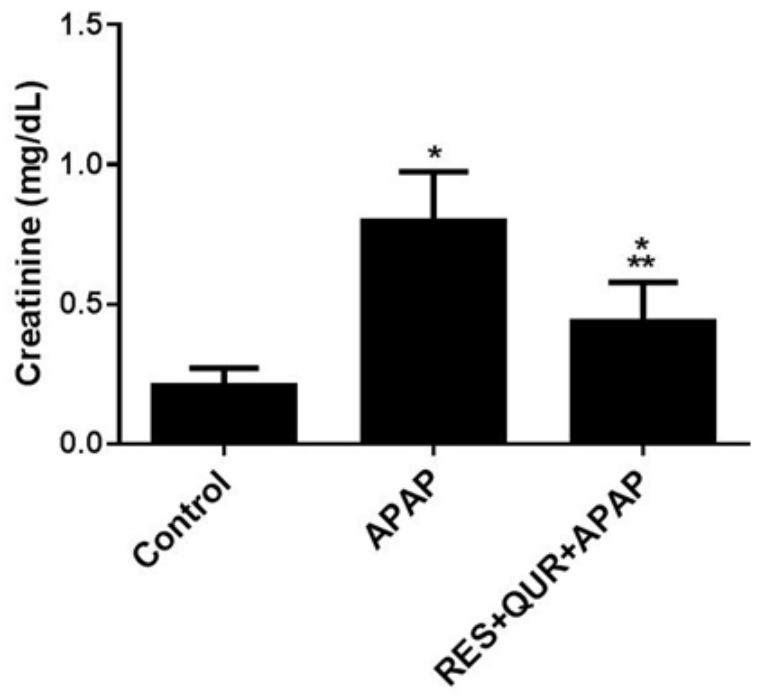

Fig. 3. Resveratrol and quercetin inhibit APAP-induced biomarkers of kidney injury in rats. Blood levels of urea (A) and creatinine (B) were measured at the end of the experiment in different groups of rats used in this study; Control group, APAP group, and RES+QUR+APAP group. Results represent the mean $( \pm S D) ; n=6$ for each group. Experiments were performed in triplicate. $* \mathrm{p}<0.05$ versus control, $* * \mathrm{p}<0.05$ versus APAP.

(V) and numerous irregularly dispersed mitochondria $(\mathrm{m})$ with electron-dense matrix, markedly variable sizes and bizarre shapes. In addition, large number of lysosomes with electrondense content can be seen. Kidney cortical sections prepared For TEM analysis the control animal group (Fig. 4A) showed normal architecture of the proximal convoluted tubule with narrow lumen $(\mathrm{Lu})$ lined by tubular cuboidal cells with rounded euchromatic nuclei $(\mathrm{N})$, brush border $(\mathrm{Bb})$ of long microvilli, basal infoldings (arrow) separating elongated mitochondria $(\mathrm{m})$, resting on tubular basement membrane $(\mathrm{Bm})$. Treatment of APAP rats with RES+QUR (Figs. 4C and 4D) significantly protected these structures. However, few mitochondria (m) show bizarre shapes, vacuolated cytoplasm, and secondary lysosomes are still seen. 

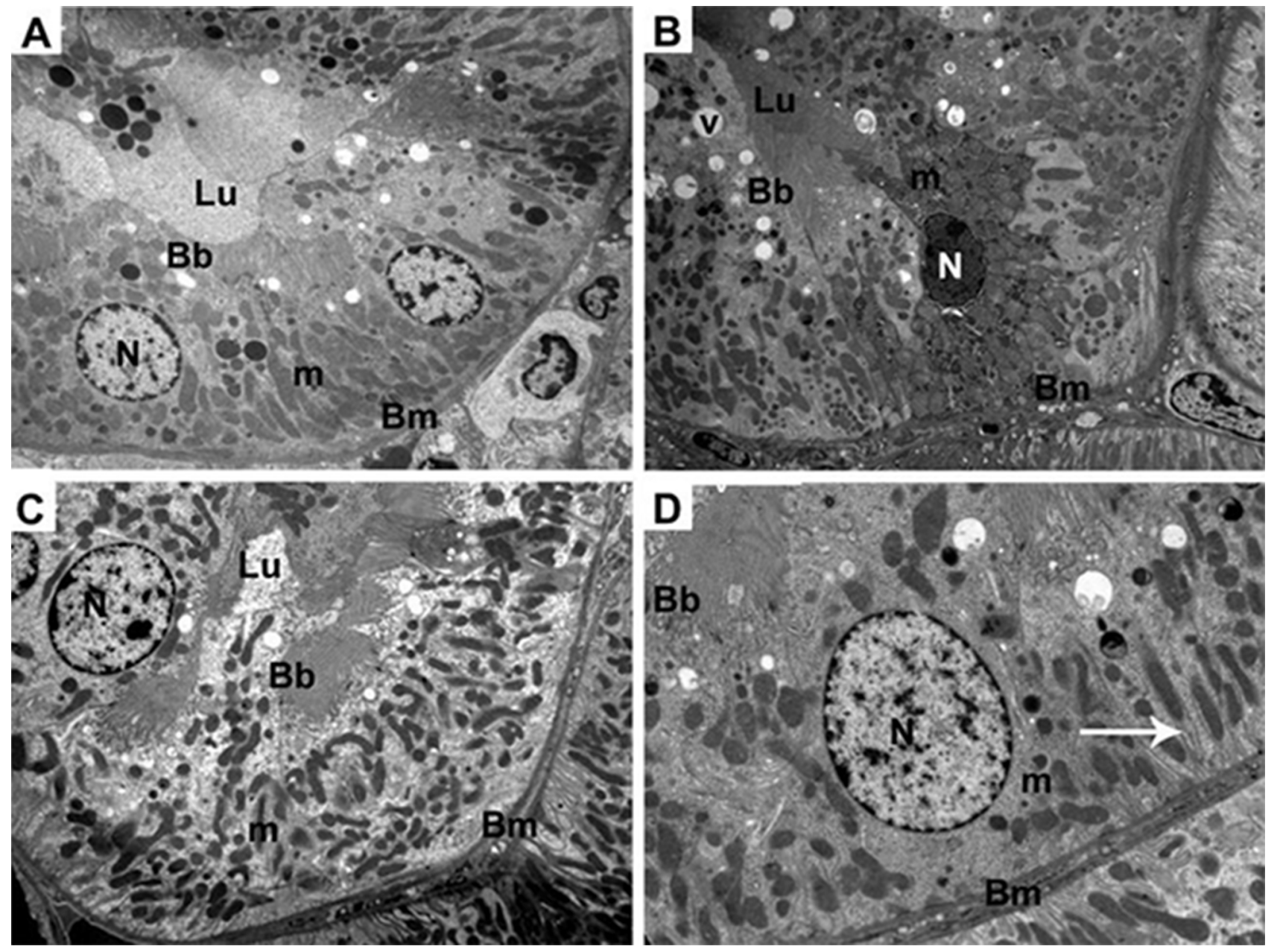

Fig. 4. Resveratrol and quercetin protect against APAP-induced proximal renal tubule damage in rats. TEM images (x2500) of the proximal convoluted tubule obtained at the end of the experiment in different groups of rats used in this study; Control group (A), APAP group (B), and RES+QUR+APAP group (C and D). Abbreviations: N, nucleus; $\mathrm{m}$, mitochondria; Lu, tubular lumen; Bb, brush border; $\mathrm{Bm}$, basement membrane; $\mathrm{V}$, vacuole.

\section{DISCUSSION}

This study investigated the ultrastructure of renal proximal convoluted tubules in APAP-induced acute kidney injury in a rat model of the disease in the presence and absence of resveratrol plus quercetin. Also, our protective approach using both compounds was also used to assess levels of inflammatory, oxidative, and kidney injury biomarkers. Therefore, rats were pre-treated for 7 days with resveratrol plus quercetin prior to the induction of acute kidney injury by APAP overdose. Here, we report (i) the ability of APAP overdose to induce profound renal tubular ultrastructural alterations; and (ii) the ability of resveratrol plus quercetin to inhibit these ultrastructural alterations, and inhibit the induction of biomarkers of inflammation, oxidative stress, and kidney injury biomarkers, blood urea and creatinine in APAP-induced acute nephrotoxicity in rats. Our results were thus consistent with our working hypothesis that APAP can induce alterations to the proximal tubules ultrastructure, and the combined polyphenolic compounds, resveratrol (RES) and quercetin (QUR) can substantially protect against renal ultrastructural damage caused by a toxic dose of APAP in a rat model of APAP-induced acute kidney injury. Interestingly, this is the first report on alterations to the proximal convoluted tubules ultrastructure induced by APAP overdose in both humans and animal models.

Our data that points to the renal proximal tubule and glomerulus ultrastructural changes induced by APAP (Figs. 1 and 4 , and data not shown) are in agreement with previous 
reports that showed certain nephrotoxic drugs and chemicals such as carbon tetrachloride (Hermenean et al., 2013) and cisplatin (Nasr, 2013), which were capable of inducing ultrastructural alterations to the glomerulus and proximal convoluted tubule. In addition, our data that points to the beneficial effects of resveratrol plus quercetin which ameliorate the deleterious effects of APAP are in agreement with previously published studies that showed resveratrol protects against several types of renal injury induced by several methods such as diabetic nephropathy, drug-induced injury, and aldosterone-induced renal injury (Kitada \& Koya, 2013), and quercetin improved renal function and protected the kidney in a rat model of adenine-induced chronic kidney disease (Yang et al., 2018).

Our protective approach that effectively blocked the damaging effects of APAP-induced nephrotoxicity, which were also associated with the suppression of kidney injury biomarkers, highlight the potential efficacy of RES+QUR in controlling, for example, kidney injury complications which can arise from the requirement of administering high doses of APAP for a long period of time to patients with chronic illnesses in order to continuously replenish the body with antioxidants that detoxify NAPQI. Indeed, the adverse effects of APAP can be ameliorated by the antioxidant Nacetylcysteine (NAC), which increases GSH and detoxifies NAPQI (Prescott et al., 1977; Hinson et al., 2010).

In summary, we have demonstrated that a toxic dose of APAP is able to induce profound renal tubular ultrastructural alterations, and pre-treatment with resveratrol plus quercetin can effectively protect against acute kidney injury and reduce blood urea, creatinine, and biomarkers of inflammation and oxidative stress in a rat model of APAPinduced nephrotoxicity.

\section{ACKNOWLEDGEMENTS}

The authors would like to thank Dr. Mariam Al-Ani from Dental Care Partnership, Sutton Coldfield, Birmingham, UK for proofreading the manuscript.

HAIDARA, M. A.; AL-ANI, B.; EID, R. A.; MOHAMMED, M. E.D.; AL-HASHEM, F. \& DALLAK, M. El acetaminofeno induce alteraciones en la ultraestructura tubular renal en un modelo de rata con nefrotoxicidad aguda protegida por resveratrol y quercetina sip. Int. J. Morphol., 38(3):585-591, 2020.

RESUMEN: El objetivo de este trabajo fue estudiar la nefrotoxicidad inducida por acetaminofeno (también llamado paracetamol o APAP) después de la ingestión accidental o inten- cional de una sobredosis de la droga. Las alteraciones ultraestructurales tubulares renales inducidas por sobredosis de APAP asociadas con la inducción de biomarcadores de daño renal no se han investigado. Además, estudiamos si los agentes combinados antiinflamatorios y antioxidantes polifenólicos, el resveratrol (RES) y la quercetina (QUR) pueden proteger contra la lesión renal aguda inducida por APAP. El grupo modelo de ratas recibió una dosis única de APAP $(2 \mathrm{~g} / \mathrm{kg})$, mientras que el grupo protector de ratas se trató previamente durante 7 días con dosis combinadas de RES (30 mg / kg) y QUR (50 mg / kg) antes de recibir una dosis única de APAP. Todas las ratas se sacrificaron un día después de la ingestión de APAP. Los tejidos renales fueron preparados para el análisis a través de la microscopía electrónica de transmisión (MET). En las muestras de sangre se determinaron la urea, creatinina y los biomarcadores de inflamación y estrés oxidativo. Las imágenes MET y el análisis químico de la sangre mostraron que la sobredosis de APAP inducía daño renal, como lo demuestran las alteraciones sustanciales en la ultraestructura del túbulo contorneado proximal, y además, de un aumento significativo ( $p$ $<0,05)$ de la urea, creatinina, factor de necrosis tumoral alfa y niveles sanguíneos de malondialdehído, protegidos por RES + QUR. Estos hallazgos indican que APAP induce alteraciones en la ultraestructura tubular renal, inhibida por el resveratrol más quercetina, que también disminuye los niveles sanguíneos de biomarcadores de daño renal.

PALABRAS CLAVE: Ultraestructura del túbulo renal; Acetaminofeno; Resveratrol; Quercetina; Modelo de rata.

\section{REFERENCES}

Al-Ani, B. Resveratrol inhibits proteinase-activated receptor-2-induced release of soluble vascular endothelial growth factor receptor- 1 from human endothelial cells. EXCLI J., 12:598-604, 2013.

Blazka, M. E.; Elwell, M. R.; Holladay, S. D.; Wilson, R. E. \& Luster, M. I. Histopathology of acetaminophen-induced liver changes: role of interleukin 1 alpha and tumor necrosis factor alpha. Toxicol. Pathol., 24(2):181-9, 1996.

Burda, S. \& Oleszek, W. Antioxidant and antiradical activities of flavonoids. J. Agric. Food Chem., 49(6):2774-9, 2001.

Cudmore, M. J.; Ramma, W.; Cai, M.; Fujisawa, T.; Ahmad, S.; Al-Ani, B \& Ahmed,A. Resveratrol inhibits the release of soluble fms-like tyrosine kinase (sFlt-1) from human placenta. Am. J. Obstet. Gynecol., 206(3):253.e10-5, 2012.

Dallak, M. A.; Al-Ani, B.; El Karib, A. O.; Abd Ellatif, M.; Eid, R. A.; AlAni, R.; Mahmoud, H. M. \& Haidara, M. A. Exercise augments the modulatory effects of vitamin E on pre-diabetes-induced aortopathy: a potential role of adiponectin. Arch. Physiol.Biochem., 1-7, 2018. Doi: 10.1080/13813455.2018.1538250

Faghihzadeh, F.; Hekmatdoost, A. \& Adibi, P. Resveratrol and liver: a systematic review. J. Res. Med.Sci., 20(8):797-810, 2015.

Hawton, K.; Simkin, S.; Deeks, J.; Cooper, J.; Johnston, A.; Waters, K.; Arundel, M.; Bernal, W.; Gunson, B.; Hudson, M.; et al. UK legislation on analgesic packs: before and after study of long term effect on poisonings. B. M.J., 329(7474):1076, 2004.

Henderson, C. J.; Wolf, C. R.; Kitteringham, N.; Powell, H.; Otto, D. \& Park, B. K. Increased resistance to acetaminophen hepatotoxicity in mice lacking glutathione s-transferase pi. Proc. Natl. Acad. Sci. U. S A., 97(23):12741-5, 2000. 
Hermenean, A.; Ardelean,A.; Stan, M.; Herman, H.; Mihali, C. V.; Costache, M. \& Dinischiotu, A. Protective effects of naringenin on carbon tetrachloride-induced acute nephrotoxicity in mouse kidney. Chem. Biol. Interact., 205(2):138-47, 2013

Hinson, J. A.; Reid, A. B.; McCullough, S. S. \& James, L. P. Acetaminopheninduced hepatotoxicity: role of metabolic activation, reactive oxygen/ nitrogen species, and mitochondrial permeability transition. Drug Metab. Rev., 36(3-4):805-22, 2004.

Hinson, J. A.; Roberts, D. W. \& James, L. P. Mechanisms of acetaminopheninduced liver necrosis. Handb. Exp. Pharmacol, (196):369-405, 2010.

Hung, L. M.; Chen, J. K.; Huang, S. S.; Lee, R. S. \& Su, M. J. Cardioprotective effect of resveratrol, a natural antioxidant derived from grapes. Cardiovasc. Res., 47(3):549-55, 2000.

James, L. P.; Mayeux, P. R. \& Hinson, J. A. Acetaminophen-induced hepatotoxicity. Drug Metab. Dispos., 31(12):1499-506, 2003.

Karaali, H. F.; Fahmi, R. R. \& Borjac, J. M. Effect of ocimum basilicum leaves extract on acetaminophen-induced nephrotoxicity in BALB/c mice. J. Complement. Integr. Med., 16(2), 2018. Doi: 10.1515/jcim2018-0111

Kitada, M. \& Koya, D. Renal protective effects of resveratrol. Oxid. Med. Cell. Longev., 2013:568093, 2013.

Larson, A. M.; Polson, J.; Fontana, R. J.; Davern, T. J.; Lalani, E.; Hynan, L. S.; Reisch, J. S.; Schiødt, F. V.; Ostapowicz, G.; Shakil, A. O.; et al. Acetaminophen-induced acute liver failure: results of a united states multicenter, prospective study. Hepatology, 42(6):1364-72, 2005.

McGill, M. R.; Sharpe, M. R.; Williams, C. D.; Taha, M.; Curry, S. C. \& Jaeschke, H. The mechanism underlying acetaminophen-induced hepatotoxicity in humans and mice involves mitochondrial damage and nuclear DNA fragmentation. J. Clin. Invest., 122(4):1574-83, 2012.

Mour, G.; Feinfeld, D. A.; Caraccio, T. \& McGuigan, M. Acute renal dysfunction in acetaminophen poisoning. Ren.Fail., 27(4):381-3, 2005.

Nasr, A. Y. Morphological, biochemical, histological, and ultrastructural protective effects of misoprostol on cisplatin induced-hepatotoxicity in adult male rats. Saudi Med.J., 34(12):1237-47, 2013.

Ostapowicz, G.; Fontana, R. J.; Schiødt, F. V.; Larson, A.; Davern, T. J.; Han, S. H. B.; McCashland, T. M.; Shakil, A. O.; Hay, J. E.; Hynan, L.; et al. M. Results of a prospective study of acute liver failure at 17 tertiary care centers in the United States. Ann.Intern. Med., 137(12):947$54,2002$.

Prescott, L. F.; Park, J.; Ballantyne, A.; Adriaenssens, P. \& Proudfoot, A. T. Treatment of paracetamol (acetaminophen) poisoning with $\mathrm{N}$ acetylcysteine. Lancet, 2(8035):432-4, 1977.

Rogerio, A. P.; Kanashiro, A.; Fontanari, C.; da Silva, E. V. G.; LucisanoValim, Y. M.; Soares, E. G. \& Faccioli, L. H. Anti-inflammatory activity of quercetin and isoquercitrin in experimental murine allergic asthma. Inflamm. Res., 56(10):402-8, 2007.

Yang, H.; Song, Y.; Liang, Y. N. \& Li, R. Quercetin treatment improves renal function and protects the kidney in a rat model of adenine-induced chronic kidney disease. Med. Sci. Monit., 24:4760-6, 2018.

Zhang, J.; Sheng, Y.; Shi, L.; Zheng, Z.; Chen, M.; Lu, B. \& Ji, L. Quercetin and baicalein suppress monocrotaline-induced hepatic sinusoidal obstruction syndrome in rats. Eur. J. Pharmacol., 795:160-8, 2017.

\author{
Corresponding author: \\ Professor Mohamed Haidara \\ Department of Physiology \\ College of Medicine \\ King Khalid University \\ Abha 61421 \\ SAUDI ARABIA
}

E-mail: haidaram@hotmail.com

Received: 20-08-2019

Accepted: 19-12-2019 